\title{
Experimental analysis of lime putty and pozzolan-based mortar for interventions in archaeological sites
}

\author{
Francesca Autiero (D) - Meera Ramesh - Miguel Azenha - Marco Di Ludovico • \\ Andrea Prota $\cdot$ Paulo B. Lourenço
}

Received: 21 January 2021/Accepted: 21 June 2021 / Published online: 5 July 2021

(C) The Author(s) 2021

\begin{abstract}
The study aims at defining and characterizing a specific restoration mortar for archaeological masonry structures made with traditional materials and to assess the suitability of the mixture compared to other mortars; such a goal is crucial to develop and define interventions in the archaeological sites. The mixture was defined to ensure compatibility with ancient materials and following frequently adopted recommendations at the site, specifically by using: (1) raw materials as similar as possible to the ancient ones; (2) traditional mix design. Therefore, the mixture was made with commercial lime putty CL 90-S type and natural Phlegrean pozzolan, i.e. volcanoclastic material collected from the volcanic area located in the West of Naples in Italy. The precious and limitedly available natural pozzolan used in the experiments resulted in an exclusive mortar which is very similar to the archaeological ones. The mortar has a binder to aggregate ratio $1: 3$ by volume, according to traditional techniques typically encountered in the ancient Roman city of Pompeii and Vesuvius surrounding area. The evolution of the flexural and compressive
\end{abstract}

F. Autiero $(\varangle) \cdot$ M. Di Ludovico · A. Prota

Department of Structures for Engineering and

Architecture, DiSt, University of Naples Federico II, Via

Claudio 21, 80125 Naples, Italy

e-mail: francesca.autiero@unina.it

M. Ramesh · M. Azenha · P. B. Lourenço

Department of Civil Engineering, ISISE, University of

Minho, Campus de Azurém, 4800 Guimarães, Portugal strength, elastic modulus, bulk density, open porosity and ultrasonic pulse velocity has been monitored for up to 200 days, based on standard procedures. Moreover, the hardening process was monitored with Differential Thermal Analysis up to 90 days, through the evaluation of phase transitions associated with dehydroxylation and decarboxylation, considering different depths from the external surface of the mortar. The achieved mechanical properties were compatible with those of lime-based mixtures for repair interventions of ancient masonry structures. Moreover, the mortar was found to be well-suited to mitigate cracking, showing a low ratio between its stiffness and load capacity compared to other typologies of mortars used for masonry restoration. Ultrasonic pulse velocity test proved to be a reasonable complementary method to monitor the evolution of the hardened properties of the mortar. Carbonation was found to be still progressing at 90 days. The data presented provide useful and reliable information to approach the complex process of restoration in archeological sites.

Keywords Archaeological Pompeii site - Repair mortar · Lime putty $\cdot$ Pozzolan · Carbonation . Compressive strength · Elastic modulus · Ultrasonic pulse velocity - Differential thermal analysis 


\section{Introduction}

Restoration interventions of archaeological masonry structures and columns are often based on the use of mortars. As a material for restoration interventions, a mortar should be compatible with the ancient materials, durable and its properties should be well documented [1-3]. In absence of specific requirements for different or innovative solutions, the use of traditional materials and techniques is generally preferred due to their good compatibility with the substrate material (i.e. free thermal dilation, salt content, stiffness and strength apart from aesthetics and authenticity issues)[3]. The production of specifically devised repair mortars by mixing single raw materials on-site should be defined based on an accurate knowledge of the raw materials and the craftsmanship composing the ancient ones. However, the exact definition of the original components often presents economic and technical constraints and, when they are known, it is often impossible to find the same materials.

Several experimental studies on the production of repair mortars based on the composition of the ancient ones are available in the literature. Some studies focused on aerial lime mortars (i.e. lime putty or hydrated lime) with siliceous or calcareous sand [4-8], while others added natural or artificial pozzolanic additions or used hydraulic lime instead [9-12]. Indeed, it is known that aerial lime is one of the most ancient binders used in mortars for masonry [6, 10, 13-17]. Its hardening process takes place through evaporation and carbonation, thus it needs contact with the carbon dioxide in the atmosphere and cannot occur underwater [8]. The carbonation process is gradual and very slow, starting from the outer surface of the joints in the first days after the application until reaching the inner part of the masonry from few months up to more than a year depending on the porosity of the mortar and the units, the wall thickness and the environmental conditions, in particular the relative humidity $[7,18]$.

Pozzolanic additions have been used with aerial lime for masonry mortars, in the form of natural pozzolans (volcanic ash or specific kind of earth) or artificial ones (crushed terracotta or wood ash)since ancient times, especially in the Roman period. Such additions served the function of reacting with the lime and the water in the mixture to give it hydraulic properties, and also for improving the final strength of the mortar [9, 12-14, 18, 19]. The addition of pozzolans modifies the hardening process of air lime-based mortars, by introducing the formation of hydration products (calcium silicate hydrates and calcium silicate aluminate hydrates) similar to hydraulic lime or cementitious mortars, but with a slower rate of hardening compared to cement [20].

As concerns the Pompeii site, several studies focused on the petrographic, mineralogical and chemical characterization of ancient mortar-based materials (bedding mortars, plasters and floor mortars). They found that these materials were mainly composed of aerial lime as a binder (i.e. lime putty) and local volcanic aggregates, sometimes with crushed ceramics, limestone sand or marble powder [21-28], while the mechanical properties of such materials nowadays are still poorly studied [29].

Technical sources related to structural interventions at the Pompeii site provide indications from the authority of the site for the production of repair mortars (for instance, technical documentation related to restoration interventions at the Insula Meridionalis available from pompeiisites.org). Suggested mixtures shall be made with (1) raw materials as similar as possible to the ancient ones, i.e. lime putty and Phlegrean pozzolan, and (2) mix design consistent with traditional techniques, i.e. binder to aggregate ratio equal to $1: 3$ by volume. However, comprehensive information on the mechanical performances of this type of materials, which is essential to assess their suitability for different types of interventions and their compatibility from a structural point of view, is still lacking. Goldsworthy and Min [11] investigated similar mortars, made with aerial lime powder, pozzolan from Bacoli (within the Bay of Naples) and water, with the binder to aggregate ratio varying from $1: 1$ to $1: 4$, but they only focused on the compressive strength of the mixture. On the contrary, investigations on the evolution of several mechanical and physical properties with the time are available only with regards to other typologies of mortars for interventions on masonry structures (mainly cement-lime blended mortars).

As a part of wide research intended for the definition and implementation of suitable investigation protocols and approaches for the structural interventions at the Pompeii site [30], the present study focuses on the analysis of a repair mortar compliant with the 
abovementioned indications by following a carefully controlled procedure; accurately measuring several important mechanical and physical properties and assessing their evolution with the time; analyzing, discussing and comparing the achieved results, most of which were still not available in the literature. The mixture was made with lime putty and pozzolan from the Phlegrean area (i.e. a volcanic area located at the West of Naples, Italy), with a binder to aggregate ratio $1: 3$ by volume. The evolution of the flexural and compressive strength, elastic modulus, bulk density, open porosity and ultrasonic pulse velocity has been monitored up to 200 days, according to standard procedures. Also, the rate of the hardening process and the evolution of the carbonation front have been specifically studied through the Differential Thermal Analysis.

The significance of this research is related to the distinctiveness of the produced mixture and its similarity with the archaeological mortars, especially regarding the aggregate. Indeed, the natural pozzolan used in the experiments is a precious material whose sourcing and usage is nowadays highly controlled and limited.

\section{Outline of the experimental program}

\subsection{Overall methodology}

A repair mortar compatible with the archaeological structures was defined in this study. To this end, the mixture was defined by using: (1) raw materials as similar as possible to the ancient ones, (2) a mix design consistent with ancient traditional ones and (3) a mortar consistency suitable for workability. Then, a comprehensive investigation of the mechanical and physical properties was performed to evaluate the suitability of the mortar as a material for repair in masonry structures. The experimental program involved 13 batches of mortar, 62 prismatic or cylindrical specimens and different types of destructive and non-destructive tests carried out at different ages from 3 days up to 200 days. A total number of 201 tests were carried out. Figure 1 shows prismatic $(40 \mathrm{~mm} \times 40 \mathrm{~mm} \times 160 \mathrm{~mm}$, named "P") and cylindrical $\left(60 \mathrm{~mm} \times 120 \mathrm{~mm}\right.$, named " $\mathrm{Cyl}_{\mathrm{A}}$ " and $60 \mathrm{~mm} \times 60 \mathrm{~mm}$, named " $\mathrm{Cyl}_{\mathrm{B}}$ ") specimens used in this work, while Table 1 reports the full experimental program outline.

An explanatory nomenclature B.Ty.C.Te.x.N was assigned to each test, where:

- $\mathrm{B}$ is the number of the batch of provenance (from 1 to 13 );

- Ty is the specimen type (fresh mortar, FM, prismatic, $\mathrm{P}$, or cylindrical, $\mathrm{Cyl}_{\mathrm{A}}$ or $\left.\mathrm{Cyl}_{\mathrm{B}}\right)$;

- $\mathrm{C}$ is the curing condition (A or $\mathrm{B}$ as a function of humidity and temperature, being A standard conditions and $\mathrm{B}$ controlled carbonation conditions, further detailed below);

- Te is the performed test (Flow test, FT, Bulk Density measurement, BD, Ultrasonic Pulse Velocity test, UPV, Flexural and Compression test, FC, Open Porosity test, OP, Compression test, C, Cyclic Compression test, CC, and Differential Thermal analysis, DTA);

- $\mathrm{x}$ is the age of testing $(3,5,6,7,28,60,90$ or 200 days);

- $\mathrm{N}$ is the progressive number of the specimen $(1,2$, 3) or sample derived from the specimens for Differential Thermal Analysis (1, 2, 3, 4).

A detailed specification of the performed tests with their relative nomenclature is reported in Annex.

For the raw materials, commercially available lime putty, CL90-S type according to the standard EN 459-1 [38], was used as a binder and volcanic sand from the Phlegrean area, called "pozzolan sand" in the following, was used as an aggregate. A description and brief characterization of the raw materials is provided in Sect. 2.2.

The recommendation provided by Vitruvius in $D e$ Architectura (Liber II, 5 and Liber V, 12, 15 A.C.) and by Pliny the Elder in Naturalis Historia (Liber XXXVI, $175,77-78$ A.C.) have been taken into account for the definition of the binder to aggregate ratio of 1:3. Moreover, $111.7 \mathrm{~g}$ of extra water for each $1000 \mathrm{~g}$ of pozzolan sand was added to the mixture to obtain a workable mortar, but as stiff as possible, consistently with required performances for a repair mortar $[11,31]$. The amount of extra water was defined through subsequent attempts to achieve a plastic consistency corresponding to a flow diameter of $165 \pm 10 \mathrm{~mm}$ according to the standard EN 1015-3 [32]. For each trial of water to binder ratio, a certain amount of water was added to the mixture and the consistency was defined through the flow test [32]. 


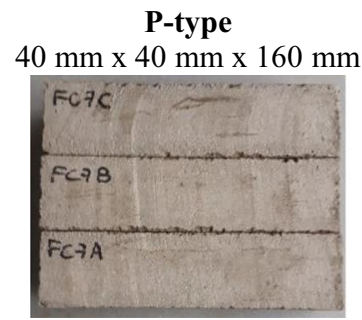

(a)

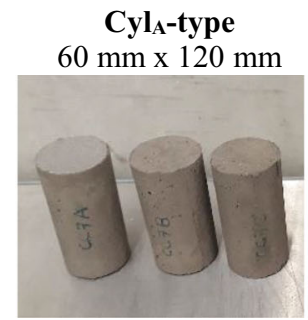

(b)

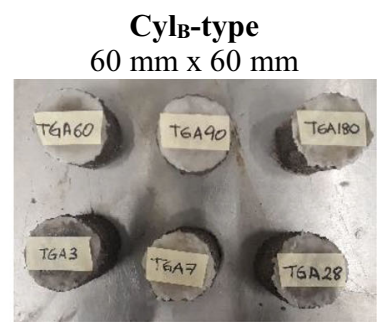

(c)

Fig. 1 Types of specimens: prismatic $40 \mathrm{~mm} \times 40 \mathrm{~mm} \times 160 \mathrm{~mm}, \mathrm{P}$ (a); cylindric $60 \mathrm{~mm} \times 120 \mathrm{~mm}$, CylA (b); cylindric $60 \mathrm{~mm} \times 60 \mathrm{~mm}, \mathrm{CylB}(\mathbf{c})$

Table 1 Experimental program outline

\begin{tabular}{|c|c|c|c|c|c|}
\hline Test & Outcomes & $\begin{array}{l}\text { Type of } \\
\text { specimen }\end{array}$ & Curing & Age (days) & $\begin{array}{l}\text { Total number of } \\
\text { tests }\end{array}$ \\
\hline FT & Flow diameter (mm) & FM & - & - & 2 \\
\hline BD & Bulk density, $\rho\left(\mathrm{kg} / \mathrm{m}^{3}\right)$ & $\mathrm{P}$ & A & $5,6,7,28,60,90,200$ & 57 \\
\hline UPV & Ultrasonic pulse velocity, $V(\mathrm{~m} / \mathrm{s})$ & $\mathrm{P}$ & A & $5,6,7,28,60,90,200$ & 57 \\
\hline FC & $\begin{array}{l}\text { Flexural and compressive strength, } f_{\mathrm{f}} \text { and } f_{\mathrm{c}} \\
(\mathrm{MPa})\end{array}$ & $\mathrm{P}$ & A & $7,28,60,90,200$ & 21 \\
\hline $\mathrm{OP}$ & Open porosity (\%) & $\mathrm{P}$ & A & $7,28,60,90,200$ & 15 \\
\hline $\mathrm{C}$ & Compressive strength, $f_{\mathrm{c}}^{*}$ (Mpa) & $\mathrm{Cyl}_{\mathrm{A}}$ & A & $7,28,60,90,200$ & 15 \\
\hline $\mathrm{CC}$ & Elastic modulus, $E$ (Mpa) & $\mathrm{Cyl}_{\mathrm{A}}$ & A & $7,28,60,90$ & 12 \\
\hline DTA & Evaluation of phase transitions & $\mathrm{FM}$ and $\mathrm{Cyl}_{\mathrm{B}}$ & $\mathrm{B}$ & $3,7,28,60,90$ & 22 \\
\hline \multicolumn{5}{|c|}{ Total number of tests } & 201 \\
\hline
\end{tabular}

The mixing procedure was performed according to the protocol provided by the standard EN 459-2 [33], by using an automatic mixer constituted of a stainless steel bowl, with $5 \mathrm{~L}$ of capacity. The starting time of the mixing process, $t_{0}$, was defined as the instant at which water came into contact with the binder in the bowl. Repair mortars are frequently prepared on-site using not standardized methods, which can involve hand mixing by using a bucket and trowel or mechanical by using an electric mortar mixer. However, standardized methods and tools were selected for this work to enhance the repeatability of the results. Once the desired consistency was achieved, the repeatability of the mixing process was checked by repeating the flow test on a new batch of mortar. Finally, the proportion of binder:aggregate:water was defined 1:3:0.5, by volume. Then, to simplify the mixing process the composition by volume was converted into weight, based on the density of the raw mate-rials (given by 275.8:1000.0:111.7 $\mathrm{g}$ for $1 \mathrm{~kg}$ of pozzolan sand).

For the test specimens, prismatic specimens $40 \mathrm{~mm} \times 40 \mathrm{~mm} \times 160 \mathrm{~mm}$ according to the standard EN 1015-11 [34] (Fig. 1a), were used for the measurement of the bulk density and the ultrasonic pulse velocity tests at 5, 6, 7, 28, 60, 90 and 200 days, flexural and compression strength tests and open porosity tests at 7, 28, 60, 90 and 200 days. Cylindric specimens $60 \mathrm{~mm} \times 120 \mathrm{~mm}, \mathrm{Cyl}_{\mathrm{A}}$-type (Fig. 1b), were used for compressive strength tests at 7, 28, 60, 90 and 200 days and cyclic compression tests for the evaluation of the elastic modulus at 7, 28, 60 and 90 days; finally, five single cylindric specimens $60 \mathrm{~mm} \times 120 \mathrm{~mm}, \mathrm{Cyl}_{\mathrm{B}}$-type (Fig. 1c), were prepared for the collection of samples to monitor the evolution of carbonation through Differential Thermal Analysis at 3, 7, 28, 60 and 90 days.

Hand compaction method was used for all the types of specimens, according to the procedure indicated in 
the standard EN 1015-11 [34] for aerial lime mortars and $40 \mathrm{~mm} \times 40 \mathrm{~mm} \times 160 \mathrm{~mm}$ prismatic specimens: the molds were filled in two almost equal layers each one compacted by twenty-five strokes of a tamper. Indeed, the method was applied also for the cylindrical specimens since hand compaction was consistent with the hand laying method of the repair mortar on-site, which does not involve vibration.

The measurement of the bulk density, ultrasonic test, flexural and compression test, open porosity test, compression and cyclic compression tests for the evaluation of the elastic modulus involved the execution of three tests for each age. The same specimens were used for the measurement of $\rho$ and $V$ at 5, 6 and 7 days and then they were used for flexural and compression tests at 7 days. For each of the following ages (i.e. 28, 60, 90 and 200 days), the same specimens were used for the measurement of $\rho$ and $V$ and finally for the flexural and compression tests. Moreover, the same three specimens were used for the cyclic compression tests at 28, 60 and 90 days.

Additional tests were performed for the assessment of the repeatability of the results. In particular, six extra $P$-type specimens were prepared from the same batch of mortar (i.e. batch 3 as reported in Appendix) and used to assess the repeatability of results with hand compaction compared to mechanical compaction. For that, three specimens were compacted by hand according to the method indicated above and three specimens were compacted by using a jolting apparatus according to the method indicated in the standards EN 459-2 and EN 196-1 [33, 35] (i.e. filling the mold in two layers each one compacted for $60 \mathrm{~s}$ ). Therefore, the mean bulk density and ultrasonic pulse velocity at 5, 6 and 7 days and the mean flexural and compressive strength obtained at 7 days of the hand compacted specimens were compared with the ones of the mechanically compacted specimens. Additionally, to check the quality of the specimens and the repeatability of the results of specimens obtained from different batches of the same mix, the measurement of $\rho$ and $\mathrm{V}$ was performed on three reference specimens at 5, 6, 7, 28, 60 and 90 days (i.e. on the specimens used for the measurement of $\rho$ and $V$ and for the flexural and compression tests at 200 days) and the values obtained were compared with the ones obtained on the specimens tested at every single age.

Differential Thermal Analysis involved the execution of four tests for each age, according to a specific order for the collection of the samples and testing, to ensure repeatability and effectiveness of the procedure as described in Sect. 2.4. Moreover, before the execution of Differential Thermal Analysis on hardened mortar, the test was performed on single raw materials and fresh mortar. For fresh mortar, two samples were collected directly from the mixing bowl at the end of the mixing processes of batch 4 and batch 5 respectively (as reported in Annex), using a metallic tip. The samples were immediately wrapped in a plastic film and stored in a controlled environment at $20 \pm 1{ }^{\circ} \mathrm{C}$ and $95 \pm 5 \%$ relative humidity. Thus, they were tested within two hours from $t_{0}$. The protocol adopted for Differential Thermal Analysis on the raw materials, fresh mortar and hardened mortar involved: a single increasing ramp, from 20 to $1100{ }^{\circ} \mathrm{C}$, with a rate of $10{ }^{\circ} \mathrm{C} / \mathrm{min}[7,9,10,36,37]$. The heating rate, $10{ }^{\circ} \mathrm{C} / \mathrm{min}$ value was selected to optimize the duration of every single test as well as the accuracy of the results, according to a common value accepted in literature [7-10, 36, 37].

The $P$-type specimens and the $\mathrm{Cyl}_{\mathrm{A}}$-type ones were stored in a controlled environment at $20 \pm 1{ }^{\circ} \mathrm{C}$ and $95 \pm 5 \%$ relative humidity up to five days, then they were demolded and cured unsealed for the remaining days up to testing in a controlled environment at $20^{\circ} \pm 1^{\circ}$ and $60 \pm 5 \%$ relative humidity, following the indications of the standard EN 1015-11 [34]. This curing method is referred to in the following as " $\mathrm{A}$ ". For the CylB-type specimens, specific preparation and curing method was adopted, to allow the carbonation process to start as soon as possible and control its progression. The specimens were cast in cylindrical molds and completely sealed with plastic tape at the top and the bottom surfaces, and stored at $20 \pm 1{ }^{\circ} \mathrm{C}$ and $95 \pm 5 \%$. Since the specimens were too fresh to remove from the cylindrical mold the first day after casting, they were demolded after two days. Thus, to ensure the carbonation process to develop only through the lateral surfaces, immediately after removing the cylindrical molds and plastic tape, the top and the bottom of the cylinders were again completely sealed by putting paraffin layers on them. Then, the specimens were cured in a controlled environment at $20 \pm 1{ }^{\circ} \mathrm{C}$ and $60 \pm 5 \%$ relative humidity. This second curing method is referred to in the following as "B". 


\subsection{Raw materials}

The choice for the selection of raw materials and mix design in this research was based on compatibility requirements with archaeological materials. Studies on ancient Roman building techniques and specific compositional analyses of archaeological mortars from Pompeii found that mortars were mainly composed of almost pure lime putty produced on-site and local volcanic aggregates [21-28]. Based on those findings, a commercial lime putty CL90-S type was selected for this work, since it ensured the least amount of impurity possible compared to the other commercially available types. Indeed, the production of the putty lime on site was not feasible for economic, logistic, time, and safety constraints. In detail, the selected putty was characterized by the following performances certified according to the specification of the standard EN 459-1 [38]: 98\% of the granulometry lower than $0.1 \mathrm{~mm}, \mathrm{CaO}+\mathrm{MgO} \geq 90 \%, \mathrm{MgO}$ $\leq 5 \%$. $\mathrm{CO} 2 \leq 4 \%$ and $\mathrm{SO} 3 \leq 2 \%$. The bulk density of the lime putty was measured according to the standard EN 1015-6 for fresh mortar [39] and resulted in $1.23 \mathrm{~g} / \mathrm{cm}^{3}$.

As concerns the aggregate, a local volcanoclastic material with variable size from ash to lapillus, collected from the Phlegrean area and called "pozzolan sand" in the following, was used in the mixture. This is a volcanic region next to the Bay of Naples where the ancient Roman builders obtained their pozzolan (traditionally known as pulvis puteolanus). The pozzolan sand had a bulk density of $1.49 \mathrm{~g} / \mathrm{cm}^{3}$, measured according to the standard EN 1097-3 [40] and a particle size distribution showed in Fig. 2, evaluated according to the standard EN 933-1 [41].

Figure 3 shows Differential Thermal Analysis thermograms of lime putty, pozzolan sand and two samples of fresh mortar. The tests confirmed the purity of the lime putty, with two main heat flow peaks related to the presence of free water and calcium hydroxide. The pozzolan sand was tested without any previous oven-drying. After a slight heat flow peak corresponding to the presence of free water, the sand did not show any significant weight loss in the present range of study. The thermograms of the two samples of fresh mortar were consistent with those for the raw materials, showing two main heat flow peaks related to the presence of free water and calcium hydroxide, respectively.

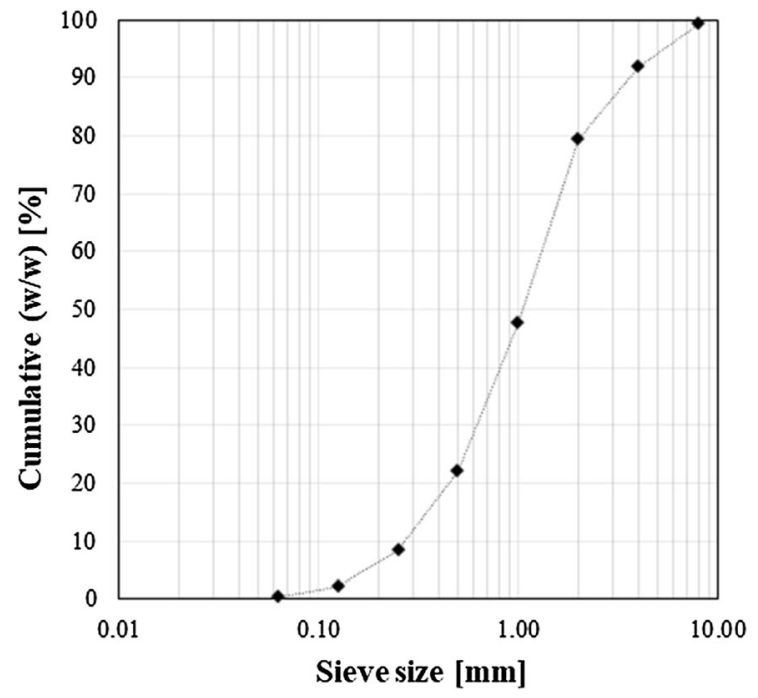

Fig. 2 Particle size distribution $(0.063-8.0 \mathrm{~mm})$ of the pozzolan sand

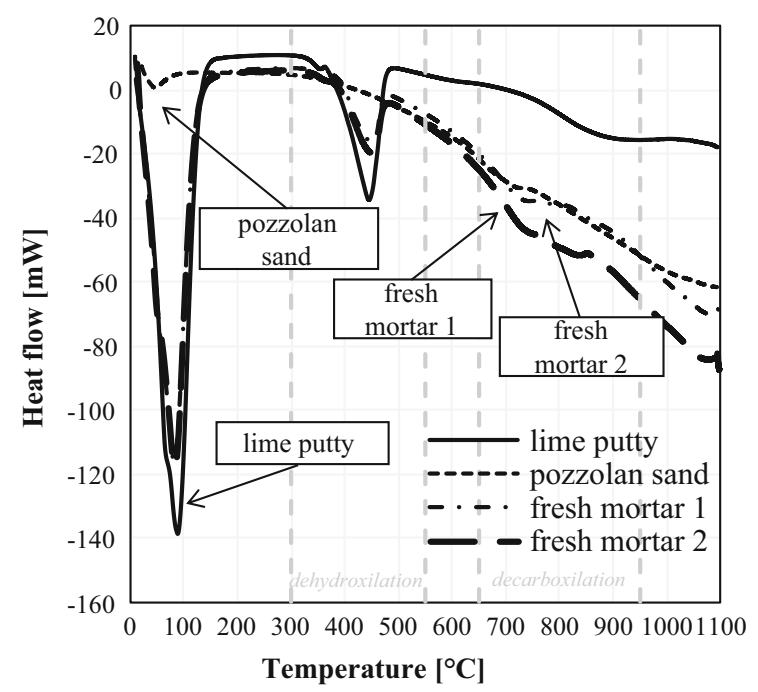

Fig. 3 Differential thermal analysis curves of lime putty, pozzolan sand and the two samples of fresh mortar tested within $2 \mathrm{~h}$ from the start of the mixing protocol

\subsection{Testing procedures of physical and mechanical properties of the hardened mortar}

At each age, the bulk density, $\rho$, was evaluated for three $P$-type specimens at first, by calculating the mean of the ratios between the weight of specimen and its volume. After that, ultrasonic tests were performed on the same specimens by positioning the probes in the 
middle of the specimen along the transversal direction, thus the path length for the calculation of the ultrasonic velocity, $V$, was equal to $40 \mathrm{~mm}$ (Fig. $4 \mathrm{a}$ ). Standard ultrasound equipment was used, with probes $25 \mathrm{~mm}$ of diameter and an operating frequency of $150 \mathrm{kHz}$. As abovementioned, The measurement of the bulk density and the ultrasonic test were also performed at each age on the reference specimens. After that, the evaluation of the flexural and compressive strength was performed according to the standard EN 1015-11 [34]. The flexural strength, $f_{\mathrm{f}}$, was evaluated from three-point bending tests performed in displacement control with a rate of $0.003 \mathrm{~mm} / \mathrm{s}$ at 7 days and $0.006 \mathrm{~mm} / \mathrm{s}$ at 28, 60, 90 and 200 days (Fig. 4b). The compressive strength, $f_{c}$, was evaluated on the two resulting halves of each prismatic specimen from the flexural test using displacement control with a rate of $0.012 \mathrm{~mm} / \mathrm{s}$ for all ages.

For the evaluation of the open porosity, at each age other three $P$-type specimens were dried, then they were subjected to water saturation in a vacuum pump (Fig. 4c). The open porosity was evaluated as the mean of the values obtained, calculated as: $\left(M_{3}-M_{1}\right)$ / $\left(M_{3}-M_{2}\right) \bullet 100$, were $M_{1}$ is the dried weight, $M_{2}$ is the immersed weight and $M_{3}$ is the saturated weight. This method was applied by adapting the recommendations RILEM TC 25-PEM for stone [42], with the time of immersion and vacuum modified to $3 \mathrm{~h}$.

The static elastic modulus, $E$, was evaluated by adapting the method presented in the standard EN 12390-13 [43] for concrete. At each age, at first, a simple compression test, $C$, was performed on three $\mathrm{Cyl}_{\mathrm{A}}$-type specimens (by using displacement control at a rate of $0.012 \mathrm{~mm} / \mathrm{s}$ ), for the evaluation of the mean maximum load and compressive strength. Then other three $\mathrm{Cyl}_{\mathrm{A}}$-type specimens were tested with five loading/unloading cycles up to one-third of the mean maximum load, in force-control with the rate defined so that the ramps lasted about $60 \mathrm{~s}$. The elastic modulus of each specimen was evaluated from the measurements of three Linear Variable Differential Transducers (LVDTs), placed at the middle of the height of the specimens, on a base of one-third on the height, being supported by two steel rings and spaced of $120^{\circ}$. Before the execution of compression and cyclic compression tests, each specimen was rectified employing thin layers of epoxy resin applied on the top and the bottom surfaces (Fig. 4d).

\subsection{Differential thermal analysis methodology for the study of the carbonation process}

For the execution of Differential Thermal Analysis, one specimen $\mathrm{Cyl}_{\mathrm{A}}$-type was cut in the middle at each age (at half of the height) and 4 samples were collected at different depths of the cut surface of one of the obtained halves, while the other half was stored in a plastic bag (Fig. 5a, b). Each sample had a volume of about $12 \mathrm{~mm} \times 12 \mathrm{~mm} \times 12 \mathrm{~mm}$ and was extracted using a metallic device with a slender tip. The samples were collected according to a pre-defined order (i.e. the first on the external surface, the second at the middle of the radius, the third at the core and the fourth on the opposite surface) (Fig. 5c).

After the collection of each sample, a pretreatment was applied to the samples to prevent the evolution of the carbonation. Such procedure was inspired by one of the two methods suggested by Scrivener [36] regarding cementitious materials for the suppression of hydration and removing soluble ions from pore

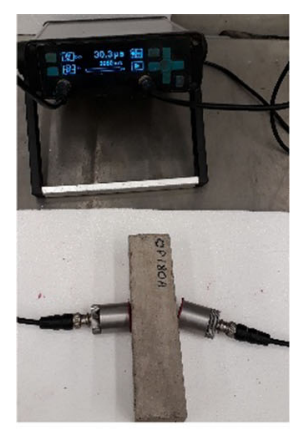

(a)

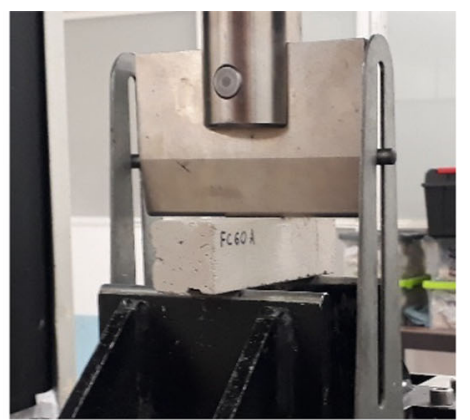

(b)

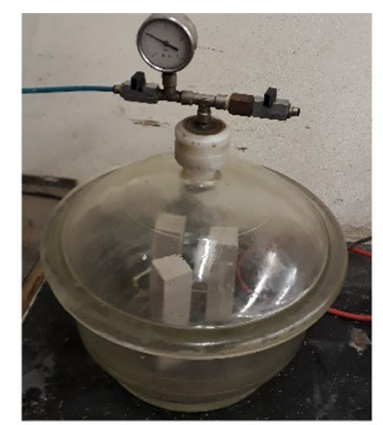

(c)

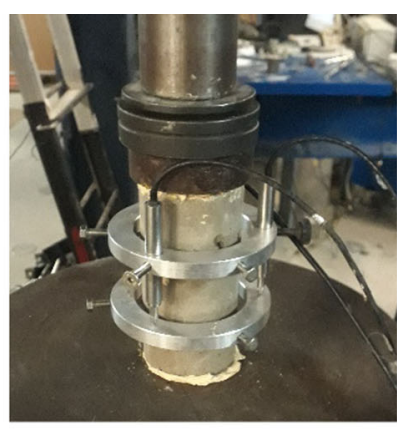

(d)

Fig. 4 Test set-ups: ultrasonic pulse velocity (a); three-point bending (b); open porosity (c); cyclic compression (d) 


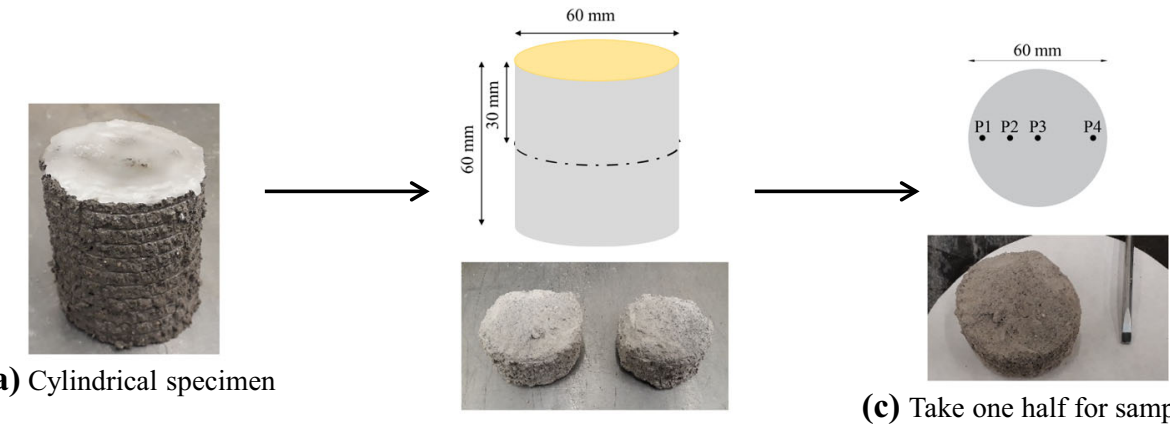

(b) Cut in half

(c) Take one half for sampling
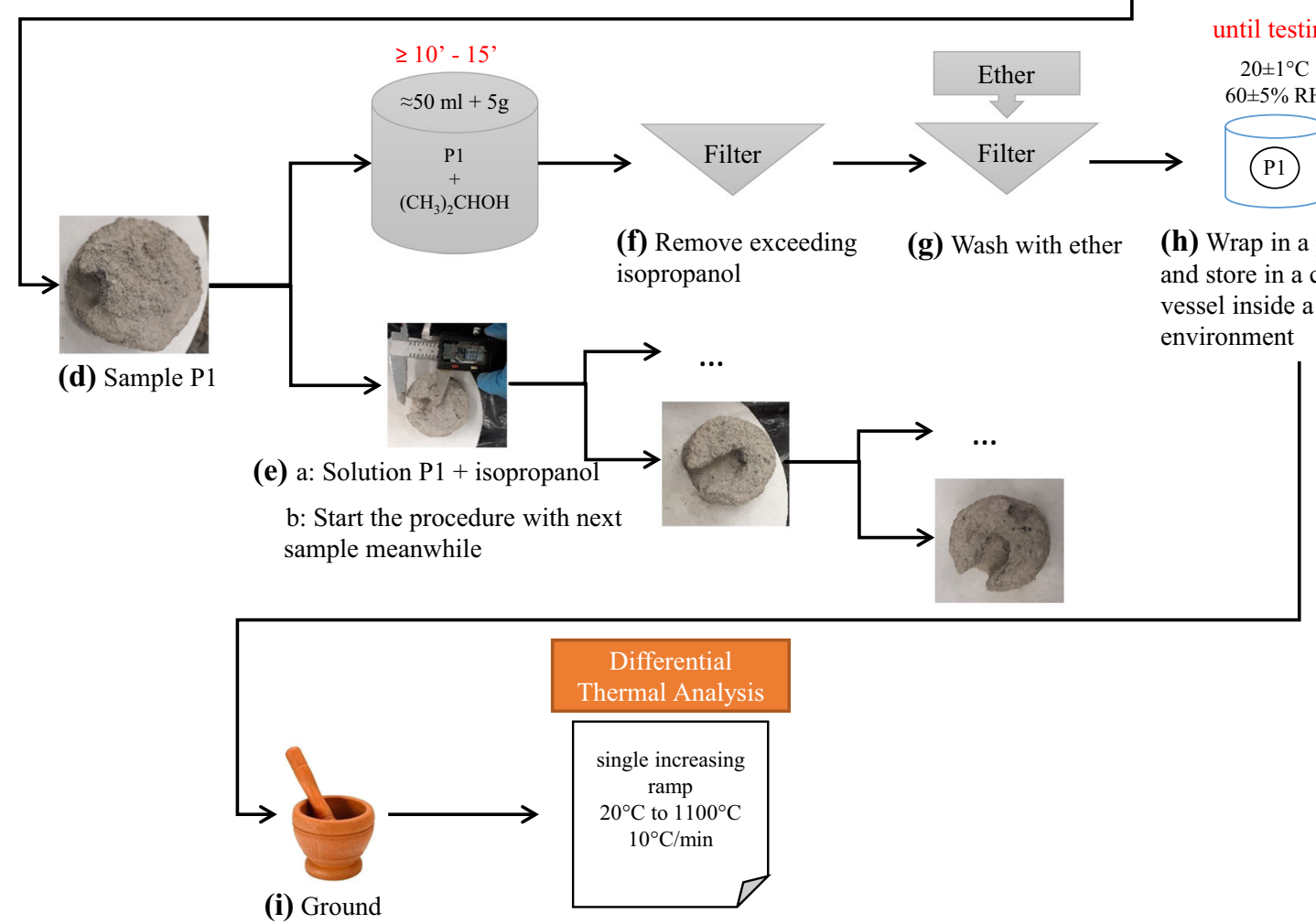

Fig. 5 Procedure flow chart for differential thermal analysis tests

solution. It was adapted for stopping carbonation to remove pore water, which is necessary for carbonation to occur [8].

Once the first sample was collected, it was immediately immersed in isopropanol $\left(\mathrm{CH}_{3}\right)_{2} \mathrm{CHOH}$ and stirred (about $50 \mathrm{ml}$ of isopropanol for $5 \mathrm{~g}$ sample), while the rest of the specimen was covered by a plastic bag. Immediately after the first sample was put in the isopropanol, the collection of the next sample started, and the procedure continued until the fourth sample in the shortest time possible (Fig. 5d, e). Each sample rested in the solution for at least $10 \mathrm{~min}$. Afterward, starting from the first sample, each solution was filtered, to remove the excess isopropanol (Fig. 5f) and washed (still above the filter device) with ether (easily volatile solvent) to replace the isopropanol (Fig. $5 \mathrm{~g}$ ). Finally, each sample was wrapped in a plastic film and stored in a closed glass vessel (of a volume of about $0.25 \mathrm{~L}$ ) inside a controlled environment at $20 \pm 1{ }^{\circ} \mathrm{C}$ and $60 \pm 5 \% \mathrm{RH}$ (Fig. 5h). All the samples were tested within a maximum of two days from the beginning of the sampling process, for the sake of consistency. Before the execution of each Differential Thermal Analysis, the sample was removed from the 
container, furtherly ground with a ceramic bowl and pestle (Fig. 5i). The tests were performed according to the same order of collection and preparation of the samples. This allowed: (1) repeatability of the procedure at the different ages; (2) assessing the effectiveness of the method applied to stop the carbonation, between samples 1 and 4 .

\section{Experimental results}

\subsection{Repeatability of results}

To assess the repeatability of results obtained with the hand compaction method compared to mechanical compaction, Table 2 reports the mean values of $\rho, V, f_{\mathrm{f}}$ and $f_{\mathrm{c}}$ with the standard deviations and coefficients of variation $(\mathrm{CoV})$ reported in brackets for hand compacted specimens and mechanically compacted ones, produced from the same batch of mortar (i.e. batch 3, as reported in Appendix). Despite a slight difference of results was detected between the two sets of specimens (i.e. $\rho$ and $V$ were higher in mechanically compacted specimens compared to hand compacted ones, the contrary happened for $f_{\mathrm{f}}$ and $f_{\mathrm{c}}$ ), they were considered acceptable compared to the variation encountered in each of the individual tests, and also comparable with the variation encountered in the tests performed in experimental studies on aerial lime mortars [7, 11,37]. Indeed, the percentage differences between the results obtained did not exceed 5\% for the bulk density and the ultrasonic pulse velocity, and about $10 \%$ for the flexural and compressive strength.

A similar conclusion has been reached as regards the repeatability of the results of specimens from different batches of mortar. Thus, Table 3 reports the
Table 3 Bulk density and ultrasonic velocities of the specimens used for flexural and compression tests at each age and of the reference specimens, with standard deviation and coefficient of variation within brackets

\begin{tabular}{llll}
\hline Age (days) & Batch & $\rho\left(\mathrm{kg} / \mathrm{m}^{3}\right)$ & $V(\mathrm{~m} / \mathrm{s})$ \\
\hline 7 & 4 & $1775(11)(0.6 \%)$ & $1239(50)(4 \%)$ \\
28 & 8 & $1785(13)(0.7 \%)$ & $1323(6)(0.4 \%)$ \\
& 5 & $1603(7)(0.4 \%)$ & $1601(41)(3 \%)$ \\
60 & 8 & $1605(19)(3 \%)$ & $1655(55)(1 \%)$ \\
& 6 & $1610(4)(0.2 \%)$ & $1598(68)(4 \%)$ \\
90 & 8 & $1616(18)(1 \%)$ & $1679(78)(5 \%)$ \\
& 7 & $1621(5)(0.3 \%)$ & $1686(20)(1 \%)$ \\
& 8 & $1620(18)(1 \%)$ & $1738(33)(2 \%)$ \\
\hline
\end{tabular}

mean values of $\rho$ and $V$ with the standard deviations and coefficients of variation reported in brackets for the specimens tested at different ages and for the reference specimens (i.e. the ones used for flexural and compression tests at 200 days as reported in Appendix). Indeed, the differences did not exceed $1 \%$ for the bulk density and $6 \%$ for the ultrasonic velocity.

\subsection{Mechanical and physical properties}

\subsubsection{Flexural and compressive strength}

Figure 6 reports the results of the strengths tests and their evolution in time. Note that the coefficients of variation are reported in brackets and the error bars in the graphs are the corresponding standard errors, calculated as the standard deviation divided by the square root of the number of experiments for each test.

Table 2 Results of the tests performed for hand compacted specimens and mechanically compacted specimens, with standard deviation and coefficient of variation within brackets

\begin{tabular}{lllllll}
\hline Batch & Age (days) & Compaction method & $\rho\left(\mathrm{kg} / \mathrm{m}^{3}\right)$ & $V(\mathrm{~m} / \mathrm{s})$ & $f_{\mathrm{f}}(\mathrm{MPa})$ & $f_{\mathrm{c}}(\mathrm{MPa})$ \\
\hline 3 & 5 & Hand & $1850(8)(0.5 \%)$ & $1208(66)(5 \%)$ & - & - \\
& & Mechanical & $1876(15)(0.8 \%)$ & $1229(29)(2 \%)$ & - & - \\
& \multirow{2}{*}{6} & Hand & $1797(16)(0.9 \%)$ & $1017(39)(4 \%)$ & - & - \\
& & Mechanical & $1835(16)(0.9 \%)$ & $1023(52)(5 \%)$ & - & - \\
& \multirow{2}{*}{7} & Hand & $1741(7)(0.4 \%)$ & $1067(45)(4 \%)$ & $0.20(0.01)(3 \%)$ & $0.62(0.08)(13 \%)$ \\
& Mechanical & $1786(11)(0.6 \%)$ & $1023(37)(4 \%)$ & $0.18(0.01)(3 \%)$ & $0.57(0.02)(3 \%)$ \\
\hline
\end{tabular}


Fig. 6 Evolution of the flexural and compressive strength

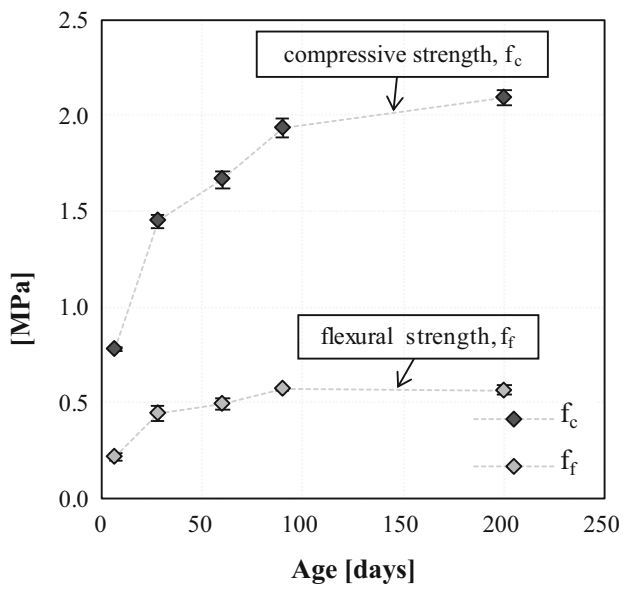

The flexural strength varied from 0.22 to $0.56 \mathrm{MPa}$ and the compressive strength varied from 0.78 to 2.10 MPa. The tests showed similar development of flexural and compressive strength. Indeed, in both cases a substantial increase was showed between 7 and 28 days, then the increase was almost constant between 28 and 90 days, and, finally, the increase was small between 90 and 200 days, with the flexural strength almost constant. These results indicated that the studied mixture developed its flexural and compressive strengths mainly in the first three months, then it slowly increased its compressive capacity up to six months. Similar trends were found in other studies on aerial lime mortars $[8,10,11]$.

\subsubsection{Open porosity}

The mean values of open porosity along with the coefficients of variation at each age are reported in Table 4. No significant variation of the open porosity with the time was detected, except for a slight reduction detected at 200 days. The mean value of the open porosity resulted in $39.6 \%$, with $\mathrm{CoV}$ of $0.8 \%$. However, a slightly decreasing trend was observed from 60 up to 200 days. These values and trends are consistent with the ones obtained on similar mortars by Faria et al. [44]. Mortars made with lime putty typically have higher open porosity compared to mortars made with hydrated lime and lime-cement blended, due to the higher amount of water in such mixtures [12, 45]. Indeed, Cizer [12] found the open porosity of lime putty mortar at 90 days to be $4-7 \%$ higher than hydrated lime mortar for different curing conditions.

\subsubsection{Ultrasonic pulse velocity and bulk density}

The bulk density and ultrasonic velocity at each age for the reference specimens are reported in Fig. 7. Note that the coefficients of variation are reported in brackets and the error bars in the graphs are the corresponding standard errors.

The ultrasonic pulse velocity reduced between 5 and 6 days, then it increased up to 90 days and decreased again between 90 and 200 days. The higher velocity at 5 days compared to 6 days was probably related to the higher humidity of the specimens. Indeed, it is known that ultrasonic velocity is higher in water than in air, thus in water-saturated porous media [46]. After that, the increase up to 90 days, was probably related to the build-up of the solid skeleton. Indeed, it is also known that the ultrasonic velocity is higher in solids than in air [46]. Finally, the reduction

Table 4 Results of the open porosity tests

\begin{tabular}{llllll}
\hline Age (days) & 7 & 28 & 60 & 90 & 200 \\
\hline Open porosity & $39.8 \%(0.8 \%)$ & $39.4 \%(0.8 \%)$ & $39.9 \%(0.5 \%)$ & $39.2 \%(1 \%)$ & $38.3 \%(0.5 \%)$ \\
\hline
\end{tabular}


Fig. 7 Evolution of the ultrasonic pulse velocity and bulk density

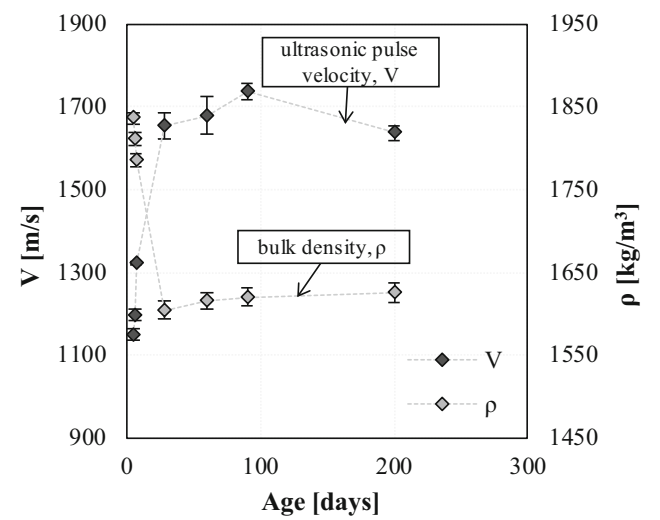

of the velocity between 90 and 200 days was probably related to the loss of water in the specimens.

As expected the bulk density showed a decreasing trend until 28 days, due to the evaporation of water, then a slight increase until 200 days, due to the carbonation process with the formation of calcium carbonate in place of calcium hydroxide, with a higher molar mass compared to the latter [36]. This latter trend was consistent with the decrease observed for the open porosity and the subsequent increase of ultrasonic velocity.

Both for bulk density and ultrasonic velocity the maximum variation was observed between 7 and 28 days, similarly to the flexural and compressive strength.

\subsubsection{Static elastic modulus}

The mean static elastic modulus at each age is reported in Fig. 8, with the coefficients of variation in brackets and the error bars in the graphs corresponding to the standard errors. The elastic modulus increased

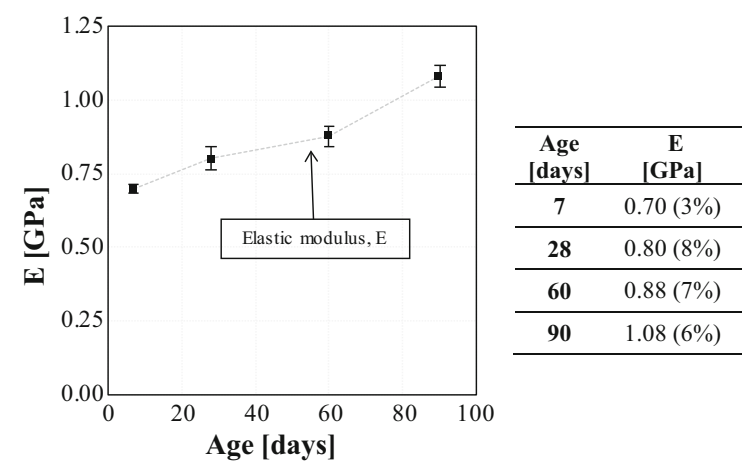

Fig. 8 Evolution of the elastic modulus with time between 7 and 90 days from 0.70 to $1.08 \mathrm{GPa}$. Aggelakopoulou [6] found lower static elastic modulus for lime putty mortars with siliceous and calcareous sand at 18 months of curing (i.e. 0.11 and $0.13 \mathrm{GPa}$ ). These different results could be related to the different aggregates used in the mixtures (see also Sect. 4).

\subsection{Differential thermal analyses}

Figure 9 shows Differential Thermal Analysis thermograms obtained from the sample P1 of each cylindrical specimen (i.e. from the surface of each specimen) at each age. A heat flow peak related to the dehydroxylation was evident at three days, getting smaller at 7 days and almost flattened from 28 days,

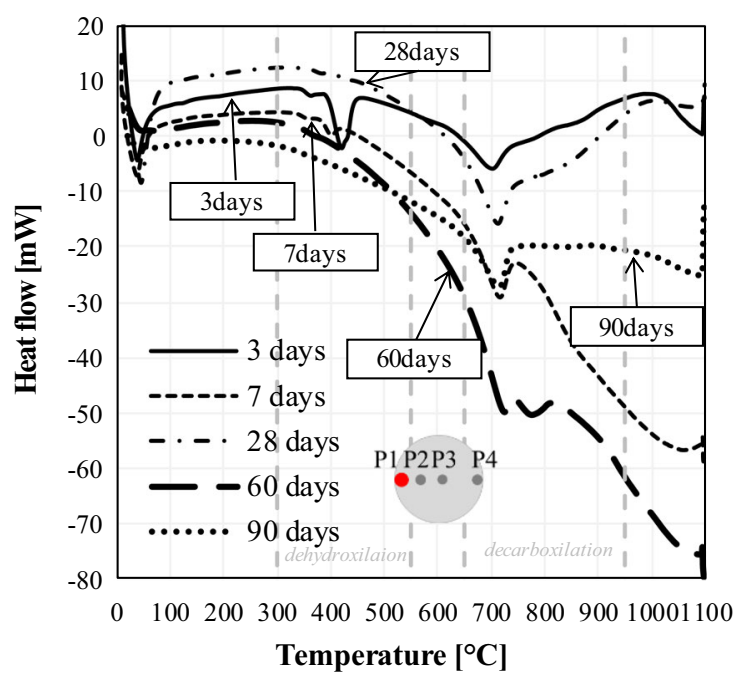

Fig. 9 Differential thermal analysis curves of samples P1 (i.e. on the surface of each cylindrical specimen) at each age 
meaning that the calcium hydroxide on the surface of the specimens was completely consumed at that age. A heat flow peak in the range of decarboxylation was observed from 3 days, with an increase in $\mathrm{CaCO}_{3}$ content, alongside the reduction of $\mathrm{Ca}(\mathrm{OH})_{2}$, indicating the evolution of carbonation. Meanwhile, a reduction of free water due to evaporation was observed. Moreover, the weight loss in the temperature range of $50-250{ }^{\circ} \mathrm{C}$ from 3 days was further analyzed to investigate the occurrence of pozzolanic reactions related to the formation of hydrated phases $[9,12]$. As no heat flow peaks were observed in that temperature range, this has led to conclude that such types of reactions were absent. Despite it was not possible to determine the reason for this unexpected outcome, this is an interesting result defining the behavior o this type of material.

As regards the evolution of carbonation through the depth of the cylindrical specimens, for the sake of simplicity, Differential Thermal Analysis curves obtained from the samples P1, P2, P3 and P4 in the first and the last ages (i.e. at 3 days and 90 days) are reported in Fig. 10. At 3 days, all the samples showed the heat flow peak in the range of dehydroxylation, while the heat flow peak in the range of decarboxylation was evident only for P1 and P4, meaning that at that age carbonation occurred only on the surface of the specimen (i.e. within a depth of about $12 \mathrm{~mm}$ ). At 90 days, the heat flow peak in the range of

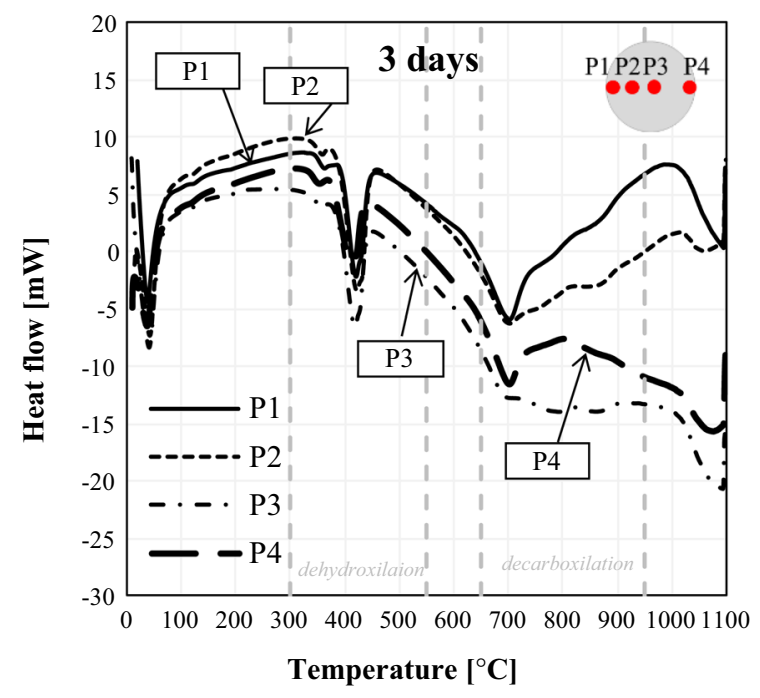

(a) dehydroxylation was observed in $\mathrm{P} 2$ and $\mathrm{P} 3$, while the peak in the range of decarboxylation was still not evident in P3. From that, it may be concluded that at that 90 days of age, carbonation was almost completed only at the edge of the specimen and was still in evolution within the core of the specimen. This was consistent with the results of thermogravimetric analyses by Lawrence et al. [47] and by literature values of carbonation depth in aerial lime mortar specimens evaluated through phenolphthalein $[7,8]$.

\section{Integrative discussion of the experimental outcomes and comparison with literature results}

A summary of the main mechanical and physical properties of the investigated mortar, with the coefficients of variation in brackets, is reported in Table 5.

Low values of mechanical parameters were found to be consistent with other lime-based mixtures for repair interventions of historical masonries, ranging about $1 \mathrm{MPa}$ and $2.3 \mathrm{MPa}$ for the compressive strength and $0.5 \mathrm{MPa}$ and $0.6 \mathrm{MPa}$ for the flexural strength after 3 months of curing [7, 10, 13]. In particular, the compressive strength was found to be compliant with the value targeted for lime-based mortar used in recent structural interventions at the Pompeii site (i.e. greater than $1.5 \mathrm{MPa}$ at 28 days) [48]. The values found also comply with the

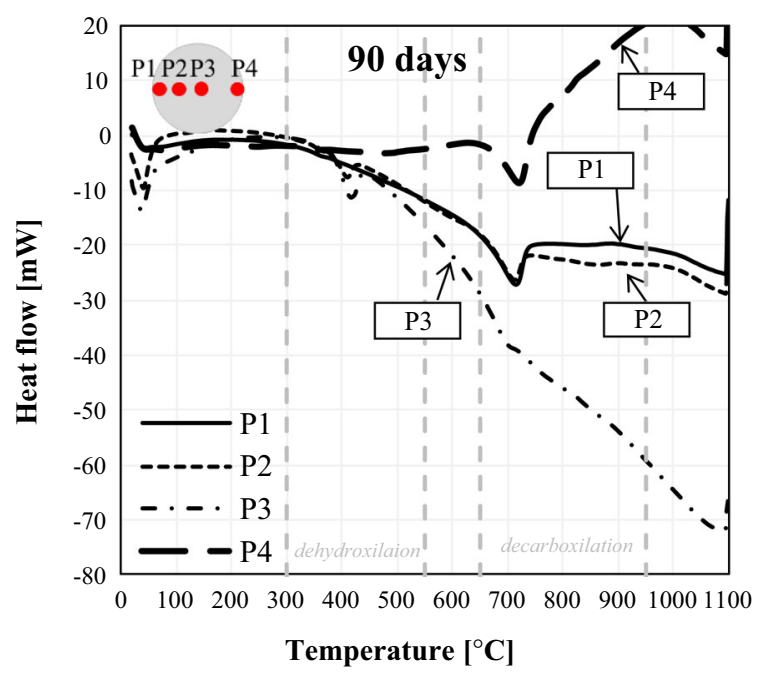

(b)

Fig. 10 Differential thermal analysis curves for all the samples at 3 days (a) and 90 days (b) 
Table 5 Summary of the investigated physical and mechanical properties

\begin{tabular}{lllllll}
\hline Age (days) & $f_{\mathrm{f}}(\mathrm{MPa})$ & $f_{\mathrm{c}}(\mathrm{MPa})$ & Open porosity $(\%)$ & $\rho\left(\mathrm{kg} / \mathrm{m}^{3}\right)$ & $V(\mathrm{~m} / \mathrm{s})$ & $E(\mathrm{GPa})$ \\
\hline 5 & - & - & - & $1836(0.7 \%)$ & $1266(2 \%)$ & - \\
6 & - & - & - & $1811(0.7 \%)$ & $1239(2 \%)$ & - \\
7 & $0.22(14 \%)$ & $0.78(4 \%)$ & $39.8 \%(0.8 \%)$ & $1785(0.7 \%)$ & $1323(0.4 \%)$ & $0.70(3 \%)$ \\
28 & $0.44(15 \%)$ & $1.45(6 \%)$ & $39.4 \%(0.8 \%)$ & $1605(1 \%)$ & $1655(3 \%)$ & $0.80(8 \%)$ \\
60 & $0.49(9 \%)$ & $1.67(7 \%)$ & $39.9 \%(0.5 \%)$ & $1616(1 \%)$ & $1679(5 \%)$ & $0.88(7 \%)$ \\
90 & $0.57(0.2 \%)$ & $1.93(6 \%)$ & $39.2 \%(1 \%)$ & $1620(1 \%)$ & $1738(2 \%)$ & $1.08(6 \%)$ \\
200 & $0.56(8 \%)$ & $2.10(4 \%)$ & $38.3 \%(0.5 \%)$ & $1625(1 \%)$ & $1637(2 \%)$ & - \\
\hline
\end{tabular}

requirement for mechanical compatibility with ancient mortars [13, 18]. Moreover, according to what was found by Faria et al. [44], the use of the lime putty in the mixture and the relatively high value of open porosity obtained may positively affect the durability of the mortar in terms of salt resistance, other than its workability. As regards the ultrasonic pulse velocity, despite it did not provide a direct correlation with the physical and mechanical properties of the mixture, its development trend was found to be a useful complementary method to follow the general development of the hardening process being consistent with the evolution of the hardened properties of the mortar.

Flexural and compressive strengths showed a similar evolution with the time. The values of the flexural strength were compared with the compressive strength at each age as reported in Fig. 11a. This could be a useful tool for a primary estimation of one of these parameters, known the other, being the flexural strength approximately equal to $30 \%$ of the compressive strength. A similar correlation was found by Haach et al. [49] for lime-cement blended mortars with different lime:cement proportions and type of aggregates.

Fig. 11 Relationship between the mean compressive strength obtained from prism halves, $f_{\mathrm{c}}$, and the mean flexural strength, $f_{\mathrm{f}},(\mathbf{a})$ and between the mean compressive strength $f_{\mathrm{c}}$ and the mean compressive strength obtained from cylindric specimens, $f_{c}^{*}$

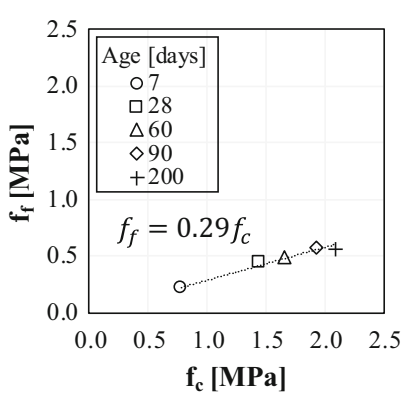

(a)
Moreover, the compressive strength obtained at each age from the standard prisms' halves (i.e. the P-type specimens), $f_{\mathrm{c}}$, were compared with the ones obtained from the cylindric specimens (i.e. $\mathrm{Cyl}_{\mathrm{A}^{-}}$ type), indicated as " $f_{\mathrm{c}} *$ ", as reported in Fig. $11 \mathrm{~b}$ and the relevant table. This correlation is particularly interesting from an engineering point of view since it is well known that the compressive strength of concrete and mortars is affected by the shape and size of the tested specimens. The ratio $f_{\mathrm{c}} * / f_{\mathrm{c}}$ was found to vary between 0.45 and 0.60 . This was consistent with what found by Parsekian [50] according to whom mortars with a strength less than $4 \mathrm{MPa}$ show a reduction of the strength of cylindrical specimens compared to prism halves between 37 and $49 \%$, which is much lower than the usual relation adopted for concrete to relate cube and cylinder specimens.

The evolution of the stiffness of a mortar (elastic modulus) compared to the evolution of its load capacity (compressive strength) could be taken as an indicator of the development of its capacity to accommodate larger movements without cracking and could be useful for comparisons with other mortars. Indeed, mortars with lower values of the

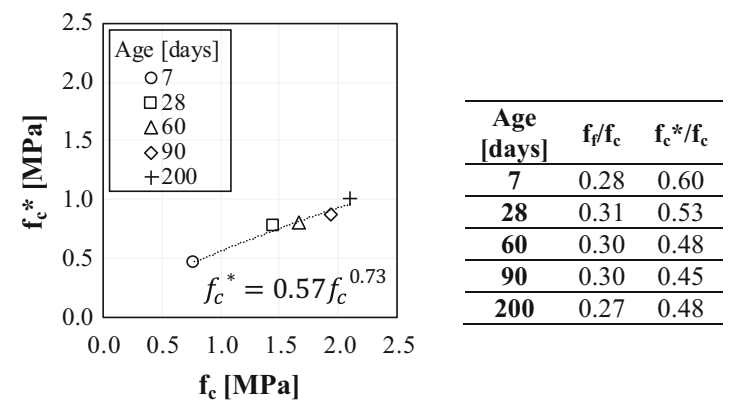

(b) 
ratio $E / f_{\mathrm{c}}$ may have a lower probability of cracking, which could be crucial in repair interventions, especially for constructions in archaeological sites which are typically characterized by a low strength capacity and high deformability. In the present study, the ratio $E / f_{\mathrm{c}}$ was found to vary in the range $900-500$, with the highest value at 7 days, as shown in Fig. 12. The figure also shows the comparison with the available data derived by literature concerning different types of mortar that can be possibly used in restoration. In particular, data related to cement-aerial lime blended mortars [45], natural hydraulic lime mortars [37] and cement-natural hydraulic lime blended mortars [49] were used for the comparison. Figure 12 also specifies the mix proportions for each mortar (Cement:Lime:Sand) and the water:binder ratio by volume. Note that as regards data from Haach et al. [49], mixtures made with fine coarse sand were considered. The mortar investigated here showed lower values of the ratio $E / f_{\mathrm{c}}$ compared to the other mixes. This provides quantitative evidence of the higher suitability of the investigated mortar for the restoration of ancient masonry structures.

\section{Conclusions}

In this study, a comprehensive characterization of a restoration mortar for ancient structures is presented. The goal of the study is the definition of indications for appropriate interventions on archaeological constructions. A mortar made with lime putty and pozzolan from the Phlegrean area, a volcanic region next to the Bay of Naples where the ancient Roman builders obtained their pozzolan (1:3 by volume) was investigated. The natural pozzolan used in the experiments is very precious and limitedly available and allowed to obtain an exclusive mortar that is very similar to the archaeological ones. The choice of the raw materials and the amount of water, the mixing procedure, the preparation and storage of the specimens are discussed in detail. The main physical and mechanical properties were investigated through standard methods at different ages from 5 up to 200 days, meanwhile, the hardening process was studied through Differential Thermal Analysis from 3 to 90 days at different depths from the surface of the cylindrical specimens. The experimental program involved 13 batches of mortar, 62 prismatic or cylindrical specimens and a total number of 201 destructive and non-destructive tests.

The main outcomes of this research can be summarized as follows:

- the mechanical properties of the mortar, specifically designed to be compatible with ancient structures, were similar to those of other types of lime-based mixtures for repair interventions of ancient masonries;

- the mean flexural and compressive strength obtained from standard prismatic $(40 \mathrm{~mm} \times 40$ $\mathrm{mm} \times 160 \mathrm{~mm})$ were found to be $0.56 \mathrm{MPa}(\mathrm{CoV}$ $8 \%)$ and $2.10 \mathrm{MPa}(\mathrm{CoV} 4 \%)$ at 200 days;

- flexural and compressive strength showed a similar increasing pattern at different ages; the flexural
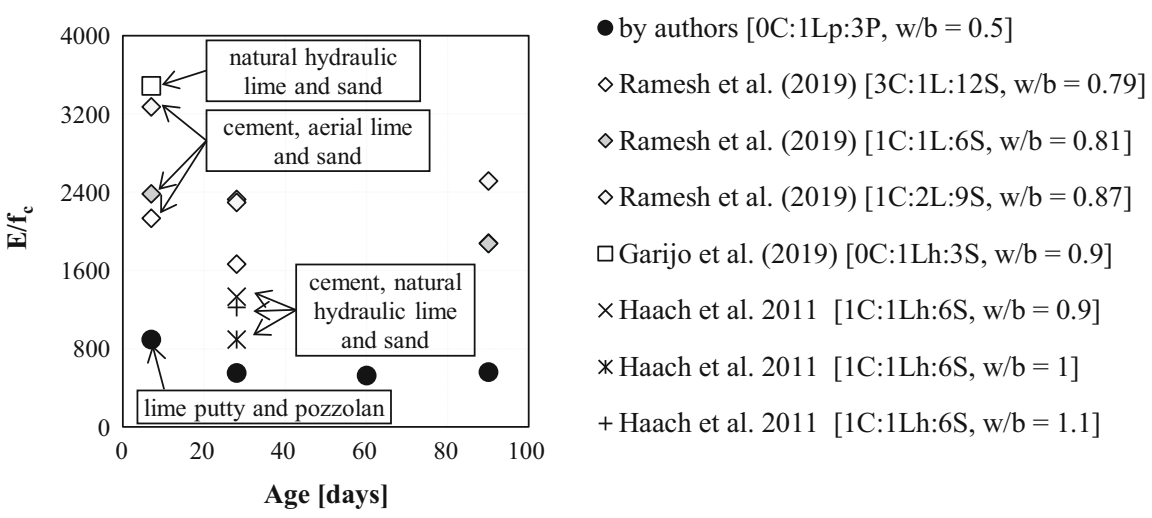

Fig. 12 Evolution of the ratio of elastic modulus to the compressive strength with time and comparison with values presented in the literature concerning different types of mixtures 
strength resulted to be approximately equal to $30 \%$ of the compressive strength;

- the compressive strength obtained from cylindric specimens was found to be approximately equal to $45-48 \%$ of the compressive strength obtained from standard prism halves between 60 and 200 days;

- the values of the ratio between the elastic modulus and the compressive strength $\left(E / f_{\mathrm{c}}\right)$, which provides a rough evaluation of the capacity of the mortar to accommodate larger movements without cracking, ranged between 0.60 at 7 days and 0.48 at 200 days and resulted to be lower than other types of mortar (i.e. cement-aerial lime blended mortars, natural hydraulic lime mortars and cement-natural hydraulic lime blended mortar) used for masonry restoration; this makes the mortar under investigation more likely to mitigate cracking in restoration works;

- open porosity was not found to be significantly affected by the hardening process, with a mean value of $39.6 \%, \mathrm{CoV}$ of $0.8 \%$. The relatively high mean value was found to be consistent with similar mortars;

- the evolution of the ultrasonic pulse velocity was found to be a reasonable complementary method for the monitoring of the development of the hardened properties of the mortar;

- Differential Thermal Analysis analysis on the surface of the specimens (until about $12 \mathrm{~mm}$ ) showed that the carbonation already started in that part from 3 days; calcium hydroxide was mainly consumed between 3 and 7 days, then the carbonation degree slowly increased until 60 days;

- Differential Thermal Analysis performed across the surface of the specimens showed that carbonation was still in evolution at intermediate depth (between approximately 12 and $24 \mathrm{~mm}$ ) and in the core of the specimens at 90 days.

This study intended to provide a reliable framework for the design of structural interventions in archaeological sites based on the use of a mortar produced onsite from single raw materials. The designed mixture is intended to fulfill both the physical and mechanical compatibility with the archaeological structures and to comply with the traditional techniques found in ancient Roman cities in the area of Naples and similar archaeological contexts.

Acknowledgements This study was carried out within the frame of the $\mathrm{PhD}$ research program in Industrial Product and Process Engineering, at the University of Naples Federico II. It was developed during a research visit at the University of Minho (Guimaraes, Portugal). The authors wish to thank the funding provided by the Portuguese Foundation for Science and Technology FCT/MCTES through national funds (PIDDAC) under the R\&D Unit Institute for Sustainability and Innovation in Structural Engineering (ISISE), under reference UIDB/ 04029/2020 and by national funds through FCT_Foundation for Science and Technology, under grant agreement (SFRH/BD/ 137358/2018) attributed to the second author. A special thanks to the director of Parco Archeologico di Pompei (PAP) Prof. Massimo Osanna and Arch. Annamaria Mauro, Arch. Bruno De Nigris and Dr. Alberta Martellone for the provided support and documentation.

Funding Open access funding provided by Università degli Studi di Napoli Federico II within the CRUI-CARE Agreement. This study was supported by the $\mathrm{PhD}$ research program in Industrial Product and Process Engineering, at the University of Naples Federico II attributed to the first author. Grants were also provided by the Portuguese Foundation for Science and Technology FCT/MCTES through national funds (PIDDAC) under the R\&D Unit Institute for Sustainability and Innovation in Structural Engineering (ISISE), under reference UIDB/ 04029/2020 and by national funds through FCT_Foundation for Science and Technology, under grant agreement (SFRH/BD/ 137358/2018) attributed to the second author.

\section{Declarations}

Conflict of interest The authors declare that they have no conflicts of interest.

Open Access This article is licensed under a Creative Commons Attribution 4.0 International License, which permits use, sharing, adaptation, distribution and reproduction in any medium or format, as long as you give appropriate credit to the original author(s) and the source, provide a link to the Creative Commons licence, and indicate if changes were made. The images or other third party material in this article are included in the article's Creative Commons licence, unless indicated otherwise in a credit line to the material. If material is not included in the article's Creative Commons licence and your intended use is not permitted by statutory regulation or exceeds the permitted use, you will need to obtain permission directly from the copyright holder. To view a copy of this licence, visit http://creativecommons.org/licenses/by/4.0/. 


\section{Appendix: Experimental program matrix}

\begin{tabular}{|c|c|c|c|c|c|c|}
\hline Batch & Type & Curing & Test & Age (days) & No. of tests & Nomenclature of the test \\
\hline 1 & FM & - & FT & - & 1 & 1.FM.FT.1 \\
\hline 2 & FM & - & FT & - & 1 & 1.FM.FT.2 \\
\hline \multirow[t]{14}{*}{3} & \multirow[t]{7}{*}{$\mathrm{P}$} & \multirow[t]{7}{*}{ A } & $\mathrm{BD}$ & 5 & 3 & 3.P.A.BD.5.1/2/3 \\
\hline & & & $\mathrm{BD}$ & 6 & 3 & 3.P.A.BD.6.1/2/3 \\
\hline & & & $\mathrm{BD}$ & 7 & 3 & 3.P.A.BD.7.1/2/3 \\
\hline & & & UPV & 5 & 3 & 3.P.A.UPV.5.1/2/3 \\
\hline & & & UPV & 6 & 3 & 3.P.A.UPV.6.1/2/3 \\
\hline & & & UPV & 7 & 3 & 3.P.A.UPV.7.1/2/3 \\
\hline & & & FC & 7 & 3 & 3.P.A.FC.7.1/2/3 \\
\hline & \multirow[t]{7}{*}{ P-MC* } & \multirow[t]{7}{*}{ A } & $\mathrm{BD}$ & 5 & 3 & 3.P-MC.A.BD.5.1/2/3 \\
\hline & & & BD & 6 & 3 & 3.P-MC.A.BD.6.1/2/3 \\
\hline & & & $\mathrm{BD}$ & 7 & 3 & 3.P-MC.A.BD.7.1/2/3 \\
\hline & & & UPV & 5 & 3 & 3.P-MC.A.UPV.5.1/2/3 \\
\hline & & & UPV & 6 & 3 & 3.P-MC.A.UPV.6.1/2/3 \\
\hline & & & UPV & 7 & 3 & 3.P-MC.A.UPV.7.1/2/3 \\
\hline & & & $\mathrm{FC}$ & 7 & 3 & 3.P-MC.A.FC.7.1/2/3 \\
\hline \multirow[t]{9}{*}{4} & FM & - & DTA & Within $2 \mathrm{~h}$ from $\mathrm{t}_{0}$ & 4 & 4.FM.DTA.1 \\
\hline & \multirow[t]{7}{*}{$\mathrm{P}$} & \multirow[t]{7}{*}{$\mathrm{A}$} & $\mathrm{BD}$ & 5 & 3 & 4.P.A.BD.5.1/2/3 \\
\hline & & & $\mathrm{BD}$ & 6 & 3 & 4.P.A.BD.6.1/2/3 \\
\hline & & & BD & 7 & 3 & 4.P.A.BD.7.1/2/3 \\
\hline & & & UPV & 5 & 3 & 4.P.A.UPV.5.1/2/3 \\
\hline & & & UPV & 6 & 3 & 4.P.A.UPV.6.1/2/3 \\
\hline & & & UPV & 7 & 3 & 4.P.A.UPV.7.1/2/3 \\
\hline & & & FC & 7 & 3 & 4.P.A.FC.7.1/2/3 \\
\hline & $\mathrm{P}$ & A & $\mathrm{OP}$ & 7 & 3 & 4.P.A.OP.7.1/2/3 \\
\hline \multirow[t]{5}{*}{5} & FM & - & DTA & Within $2 \mathrm{~h}$ from $\mathrm{t}_{0}$ & 4 & 5.FM.DTA.2 \\
\hline & \multirow[t]{3}{*}{$\mathrm{P}$} & \multirow[t]{3}{*}{ A } & $\mathrm{BD}$ & 28 & 3 & 5.P.A.BD.28.1/2/3 \\
\hline & & & UPV & 28 & 3 & 5.P.A.UPV.28.1/2/3 \\
\hline & & & $\mathrm{FC}$ & 28 & 3 & 5.P.A.FC.28.1/2/3 \\
\hline & $\mathrm{P}$ & A & OP & 28 & 3 & 5.P.A.OP.28.1/2/3 \\
\hline \multirow[t]{4}{*}{6} & \multirow[t]{3}{*}{$\mathrm{P}$} & \multirow[t]{3}{*}{ A } & BD & 60 & 3 & 6.P.A.BD. 60.1/2/3 \\
\hline & & & UPV & 60 & 3 & 6.P.A.UPV. 60.1/2/3 \\
\hline & & & FC & 60 & 3 & 6.P.A.FC. $60.1 / 2 / 3$ \\
\hline & $\mathrm{P}$ & A & $\mathrm{OP}$ & 60 & 3 & 6.P.A.OP. 60.1/2/3 \\
\hline \multirow[t]{4}{*}{7} & \multirow[t]{3}{*}{$\mathrm{P}$} & \multirow[t]{3}{*}{ A } & BD & 90 & 3 & 7.P.A.BD.90.1/2/3 \\
\hline & & & UPV & 90 & 3 & 7.P.A.UPV.90.1/2/3 \\
\hline & & & $\mathrm{FC}$ & 90 & 3 & 7.P.A.FC.90.1/2/3 \\
\hline & $\mathrm{P}$ & A & $\mathrm{OP}$ & 90 & 3 & 7.P.A.OP.90.1/2/3 \\
\hline \multirow[t]{5}{*}{8} & \multirow[t]{5}{*}{$\mathrm{P}$} & \multirow[t]{5}{*}{ A } & BD & 5 & 3 & 8.P.A.BD.5.1/2/3 \\
\hline & & & BD & 6 & 3 & 8.P.A.BD.6.1/2/3 \\
\hline & & & BD & 7 & 3 & 8.P.A.BD.7.1/2/3 \\
\hline & & & BD & 28 & 3 & 8.P.A.BD.28.1/2/3 \\
\hline & & & BD & 60 & 3 & 8.P.A.BD.60.1/2/3 \\
\hline
\end{tabular}




\begin{tabular}{|c|c|c|c|c|c|c|}
\hline Batch & Type & Curing & Test & Age (days) & No. of tests & Nomenclature of the test \\
\hline & & & $\mathrm{BD}$ & 90 & 3 & 8.P.A.BD.90.1/2/3 \\
\hline & & & $\mathrm{BD}$ & 200 & 3 & 8.P.A.BD. $200.1 / 2 / 3$ \\
\hline & & & UPV & 5 & 3 & 8.P.A.UPV.5.1/2/3 \\
\hline & & & UPV & 6 & 3 & 8.P.A.UPV.6.1/2/3 \\
\hline & & & UPV & 7 & 3 & 8.P.A.UPV.7.1/2/3 \\
\hline & & & UPV & 28 & 3 & 8.P.A.UPV.28.1/2/3 \\
\hline & & & UPV & 60 & 3 & 8.P.A.UPV.60.1/2/3 \\
\hline & & & UPV & 90 & 3 & 8.P.A.UPV.90.1/2/3 \\
\hline & & & UPV & 200 & 3 & 8.P.A.UPV.200.1/2/3 \\
\hline & & & $\mathrm{FC}$ & 200 & 3 & 8.P.A.FC.200.1/2/3 \\
\hline & $\mathrm{P}$ & A & OP & 200 & 3 & 8.P.A.OP.200.1/2/3 \\
\hline \multirow[t]{2}{*}{9} & $\mathrm{Cyl}_{\mathrm{A}}$ & A & $\mathrm{C}$ & 7 & 3 & 9.CylA.A.C.7.1/2/3 \\
\hline & $\mathrm{Cyl}_{\mathrm{A}}$ & A & $\mathrm{CC}$ & 7 & 3 & 9.CylA.A.CC.7.1/2/3 \\
\hline \multirow[t]{4}{*}{10} & $\mathrm{Cyl}_{\mathrm{A}}$ & A & $\mathrm{C}$ & 28 & 3 & 10.CylA.A.C.28.1/2/3 \\
\hline & $\mathrm{Cyl}_{\mathrm{A}}$ & $\mathrm{A}$ & $\mathrm{CC}$ & 28 & 3 & 10.CylA.A.CC.28.1/2/3 \\
\hline & & & $\mathrm{CC}$ & 60 & 3 & 10.CylA.A.CC.60.1/2/3 \\
\hline & & & $\mathrm{CC}$ & 90 & 3 & 10.CylA.A.CC.90.1/2/3 \\
\hline 11 & $\mathrm{Cyl}_{\mathrm{A}}$ & A & $\mathrm{C}$ & 60 & 3 & 11.CylA.A.C.60.1/2/3 \\
\hline \multirow[t]{2}{*}{12} & $\mathrm{Cyl}_{\mathrm{A}}$ & A & $\mathrm{C}$ & 90 & 3 & 12.CylA.A.C.90.1/2/3 \\
\hline & $\mathrm{Cyl}_{\mathrm{A}}$ & A & $\mathrm{C}$ & 200 & 3 & 12.CylA.A.C.200.1/2/3 \\
\hline \multirow[t]{5}{*}{13} & $\mathrm{Cyl}_{\mathrm{B}}$ & B & DTA & 3 & 4 & 13.CylB.B.DTA.3.1/2/3/4 \\
\hline & $\mathrm{Cyl}_{\mathrm{B}}$ & B & DTA & 7 & 4 & 13.CylB.B.DTA.7.1/2/3/4 \\
\hline & $\mathrm{Cyl}_{\mathrm{B}}$ & B & DTA & 28 & 4 & 13.CylB.B.DTA.28.1/2/3/4 \\
\hline & $\mathrm{Cyl}_{\mathrm{B}}$ & B & DTA & 60 & 4 & 13.CylB.B.DTA.60.1/2/3/4 \\
\hline & $\mathrm{Cyl}_{\mathrm{B}}$ & B & DTA & 90 & 4 & 13.CylB.B.DTA.90.1/2/3/4 \\
\hline
\end{tabular}

*MC indicates that the specimens were mechanically compacted

\section{References}

1. International Council on Monuments and Sites (2003). ICOMOS Charter-principles for the analysis, conservation and structural restoration of architectural heritage. Ratified by the ICOMOS 14th General Assembly in Victoria Falls, Victoria Falls, Zimbabwe, 27-31. https://www.icomos.org/ charters/structures_e.pdf. Accessed 08 May 2021

2. Ministero della Pubblica Istruzione (1972) Carta italiana del restauro. Circolare n 117 del 6 aprile 1972 (in Italian). 767:1-34

3. Válek J, Hughes JJ, Groot CJWP (2012) Historic mortars: characterisation, assessment and repair. A state-of-the-art summary. In: Válek J, Hughes JJ, Groot CJWP (eds) Historic mortars. RILEM bookseries, vol 7. Springer, Dordrecht, pp 1-12. https://doi.org/10.1007/978-94-007-46350_1

4. Baronio G, Binda L, Saisi A (1999) Mechanical and physical behaviour of lime mortars reproduced after the characterisation of historic mortar. In: Bartos P, Groot C and Hughes JJ (eds) RILEM international workshop historic mortars: characteristic and tests, RILEM Publications SARL, pp 307-325. https://www.rilem.net/publication/ publication/17?id_papier $=1588$

5. Balksten K, Steenari B-M (2008) A method to recreate historic mortars applied at Norrlanda church on the Island of Gotland, Sweden. In: Proceedings of historical mortars conference HMC-2008, Lisbon, Portugal 2008. https:// www.diva-portal.org/smash/get/diva2:704008/ FULLTEXT01.pdf

6. Aggelakopoulou E, Bakolas A, Moropoulou A (2019) Lime putty versus hydrated lime powder: Physicochemical and mechanical characteristics of lime based mortars. Constr Build Mater 225:633-641. https://doi.org/10.1016/j. conbuildmat.2019.07.218

7. Oliveira MAN (2015) A multi-physics approach applied to masonry structures with non-hydraulic lime mortars. Dissertaion, University of Minho

8. Lawrence RMH (2006) A study of carbonation in non-hydraulic lime mortars. Dissertaion, University of Bath

9. Moropoulou A, Bakolas A, Aggelakopoulou E (2004) Evaluation of pozzolanic activity of natural and artificial 
pozzolans by thermal analysis. Thermochim Acta 420:135-140. https://doi.org/10.1016/j.tca.2003.11.059

10. Moropoulou A, Bakolas A, Moundoulas P et al (2005) Strength development and lime reaction in mortars for repairing historic masonries. Cem Concr Compos 27:289-294. https://doi.org/10.1016/j.cemconcomp.2004. 02.017

11. Goldsworthy H, Min Z (2008) Mortar studies towards the replication of roman concrete. Archaeometry 6:932-946. https://doi.org/10.1111/j.1475-4754.2008.00450.x

12. Cizer O (2009) Competition between carbonation and hydration on the hardening of calcium hydroxide and calcium silicate binders. Dissertation, KU Leuven University

13. Lindqvist JE, van Balen K, Bicer-Simsir B et al (2009) Rilem TC 203-RHM: repair mortars for historic masonry. Testing of hardened mortars, a process of questioning and interpreting. Mater Struct Constr 42:853-865. https://doi. org/10.1617/s11527-008-9455-X

14. Lancaster LC (2005) Concrete vaulted construction in imperial Rome: Innovations in context. Cambridge University Press, Cambridge. https://doi.org/10.1017/ CBO9780511610516

15. Lancaster LC (2015) Innovative vaulting in the architecture of the roman empire: 1 st to 4 th centuries CE. Cambridge University Press, Cambridge. https://doi.org/10.1017/ CBO9781107444935

16. Giuliani CF (2018) L'edilizia nell'antichità, (in Italian). Carocci, Rome

17. Adam JP (2014) L'arte di costruire presso i romani. Materiali e tecniche, (in Italian), Longanesi, Milan

18. Maurenbrecher AHP, Trischuk K, Rousseau MZ (2001) Review of factors affecting the durability of repointing. In: 9th Can Mason symposium, pp 1-12. http:// canadamasonrydesigncentre.com/download/9th_ symposium/MORTAR07.pdf. Accessed 08 May 2021

19. Papayanni I, Pachta V, Stefanidou M, Konopissi S (2012) Survey of technological characteristics of structural mortars of different historical periods. In: Jasieńko J (ed) Structural analysis of historical constructions. Wrocław, pp 1248-1254

20. Walker R, Pavía S (2011) Physical properties and reactivity of pozzolans, and their influence on the properties of limepozzolan pastes. Mater Struct Constr 44:1139-1150. https:// doi.org/10.1617/s11527-010-9689-2

21. Piovesan R, Curti E, Grifa C et al (2009) Petrographic and microstratigraphic analysis of mortar-based building materials from the Temple of Venus, Pompeii. In: Quinn PS (ed) Interpreting silent artefacts: petrographic approaches to archaeological ceramics. Archaeopress, Oxford, pp 65-79

22. Miriello D, Bloise A, Crisci GM et al (2018) New compositional data on ancient mortars and plasters from Pompeii (Campania-Southern Italy): Archaeometric results and considerations about their time evolution. Mater Charact 146:189-203. https://doi.org/10.1016/j.matchar.2018.09. 046

23. Izzo F, Arizzi A, Cappelletti P et al (2016) The art of building in the Roman period (89 B.C. -79 A.D.): Mortars, plasters and mosaic floors from ancient Stabiae (Naples, Italy). Constr Build Mater 117:129-143. https://doi.org/10. 1016/j.conbuildmat.2016.04.101
24. La Russa MF, Ruffolo SA, Ricca M et al (2015) Archaeometric approach for the study of mortars from the underwater archaeological site of Baia (Naples) Italy: preliminary results. Period di Mineral 84:553-567. https://doi.org/10. 2451/2015PM0031

25. Leone G, De Vita A, Magnani A, Rossi C (2016) Characterization of archaeological mortars from Herculaneum. Thermochim Acta 624:86-94. https://doi.org/10.1016/j.tca. 2015.12.003

26. De Luca R, Miriello D, Pecci A et al (2015) Archaeometric study of mortars from the Garum Shop at Pompeii, Campania, Italy. Geoarchaeology 30:330-351. https://doi.org/ 10.1002/gea.21515

27. Miriello D, Barca D, Bloise A et al (2010) Characterisation of archaeological mortars from Pompeii (Campania, Italy) and identification of construction phases by compositional data analysis. J Archaeol Sci 37:2207-2223. https://doi.org/ 10.1016/j.jas.2010.03.019

28. Bonazzi A, Santoro S, Mastrobattista E (2007) Caratterizzazione archeometrica delle malte e degli intonaci dell'Insula del Centenario, In: Santoro S (ed) Pompei. Insul. Del Centen. (IX, 8), I. Indagini Diagnostiche Geofis. e Anal. Archeometriche (in Italian), Ante Quem, Bologna, 2007, pp 93-128

29. Autiero F, De Martino G, Di Ludovico M, Prota A (2019) Mechanical behavior of ancient mortar specimens from Pompeii site. In: proceedings of the 7th international conference on computational methods in structural dynamics and earthquake engineering (COMPDYN 2015), Greece, Athens, pp 1251-1262. https://doi.org/10.7712/120119. 6994.18836

30. Autiero F, De Martino G, Di Ludovico M, Prota A (2020) Mechanical performance of full-scale Pompeii-like masonry panels. Constr Build Mater 251:118964. https:// doi.org/10.1016/j.conbuildmat.2020.118964

31. Negri R (2007) Alla ricerca del "saper fare" degli antichi nella Domus del Centenario, In: Santoro S (ed) Pompei. Insul. Del Centen. (IX, 8), I. Indagini Diagnostiche Geofis. e Anal. Archeometriche (in Italian), Ante Quem, Bologna, 2007, pp 129-136

32. CEN (2004) EN 1015-3 Methods of test for mortar for masonry-part 3: determination of consistence of fresh mortar (by flow table)

33. CEN (2010) EN 459-2 Building lime. Part 2: test methods

34. CEN (2007) EN 1015-11 Methods of test for mortar for masonry-Part 11: determination of flexural and compressive strength of hardened mortar

35. CEN (2005) EN 196-1 Methods of testing cement. Part 1: determination of strength

36. Scrivener K, Snellings R, Lothenbach B (2018) A practical guide to microstructural analysis of cementitious materials. CRC Press, London. https://doi.org/10.1201/b19074

37. Garijo L, Azenha M, Ramesh M et al (2019) Stiffness evolution of natural hydraulic lime mortars at early ages measured through EMM-ARM. Constr Build Mater 216:405-415. https://doi.org/10.1016/j.conbuildmat.2019. 04.258

38. CEN (2015) EN 459-1 Building lime. Part 1: definitions, specifications and conformity criteria 
39. CEN (2007) EN 1015-6 Methods of test for mortar for masonry. Part 6: DETERMINATION of bulk density of fresh mortar

40. CEN, EN 1097-3 Tests for mechanical and physical properties of aggregates. Part 3: determination of loose bulk density and voids

41. CEN (2012) EN 933-1 Tests for geometrical properties of aggragates. Part 1: determination of particle size distribution-sieving method

42. RILEM TC 25-PEM (1980) Recommended tests to measure the deterioration of stone and to assess the effectiveness of treatment methods. Mater Struct 13:175-253

43. CEN (2013) EN 12390-13 Testing hardened concrete. Part 13: determination of secant modulus of elasticity in compression

44. Faria P, Henriques F, Rato V (2008) Comparative evaluation of lime mortars for architectural conservation. J Cult Herit 9:338-346. https://doi.org/10.1016/j.culher.2008.03. 003

45. Ramesh M, Azenha M, Lourenço PB (2019) Quantification of impact of lime on mechanical behaviour of lime cement blended mortars for bedding joints in masonry systems. Constr Build Mater 229:116884. https://doi.org/10.1016/j. conbuildmat.2019.116884

46. Vasanelli E, Colangiuli D, Calia A et al (2015) Ultrasonic pulse velocity for the evaluation of physical and mechanical properties of a highly porous building limestone.
Ultrasonics 60:33-40. https://doi.org/10.1016/j.ultras.2015. 02.010

47. Lawrence RMH, Mays TJ, Walker P, D’Ayala D (2006) Determination of carbonation profiles in non-hydraulic lime mortars using thermogravimetric analysis. Thermochim Acta 444:179-189. https://doi.org/10.1016/j.tca.2006.03. 002

48. Calvanese V, Zambrano A (2021) A conceptual design approach for archaeological structures, a challenging issue between innovation and conservation: a studied case in ancient pompeii. Buildings 11(4):167. https://doi.org/10. 3390/buildings 11040167

49. Haach VG, Vasconcelos G, Lourenço PB (2011) Influence of aggregates grading and water/cement ratio in workability and hardened properties of mortars. Constr Build Mater 25:2980-2987. https://doi.org/10.1016/j.conbuildmat.2010. 11.011

50. Parsekian GA, Fonseca FS, Pinheiro GL, Camacho JS (2014) Properties of mortar using cubes, prism halves, and cylinder specimens. ACI Mater J. https://doi.org/10.14359/ 51686726

Publisher's Note Springer Nature remains neutral with regard to jurisdictional claims in published maps and institutional affiliations. 